\title{
Municipal GIS in Northern Ontario status and strategies
}

\author{
Théo Noel de Tilly
}

Geographic Information Systems (GIS) are an important tool for economic developers to capture, manipulate and interpret local data from a myriad of sources including municipal infrastructure data, land assets, local zoning by-laws, building codes, local maps and aerial photographs. This paper provides a description of GIS technologies and applications; reviews the status of municipal GIS across Northern Ontario and; presents key success elements that should be considered by municipal governments and their staff when developing GIS strategies and networks. The elements will increase the likelihood of a successful deployment and the long-term viability of the GIS solution.

Keywords: Geographic Information Systems (GIS), Northern Ontario, municipal governments.

\section{Introduction}

\section{Challenge statement and research goal}

Economic development is a process that supports the growth and vitality of a community through job creation, job retention, improved tax base and a reasonable quality of life (EDAC, 2008). An economic development professional's job is to address these challenges by creating employment opportunities and facilitating business development and expansion. This, in turn, helps improve the community's overall well-being. In order to accomplish these objectives, the economic developer must have a solid understanding of local issues and have access to a wide variety of information including municipal infrastructure data, land assets, local zoning by-laws, building codes, local maps and aerial photographs. One tool that is helping municipal workers capture, manipulate and interpret local data from a myriad of sources is a powerful technology called Geographic Information Systems (GIS).

GIS is computer-based system that allows users to capture, store, analyze and manage georeferenced data. In its crudest form, GIS has existed since the early $1960 \mathrm{~s}^{1}$ (GIS Development. 2000). During that decade, it was used primarily for scientific applications. With the introduction of personal computers (PCs) in the early 1980's, GIS became more accessible and its adoption and application grew significantly. Today, GIS is used in many different

\footnotetext{
${ }^{1}$ Cartography systems existed before the 1960s, however, the more modern computerized mapping system resembling today's GIS technology appeared in the mid-1960s when Harvard Laboratory for Computer Graphics and Spatial Analysis laid its foundation with the development of general purpose mapping software in the mid1960s.
} 
applications within the public and private sectors. Municipalities are realizing the potential benefits of GIS and many have either implemented or are investigating the feasibility of deploying the technology within their organizations. Most have discovered (or are in the process of discovering) that GIS is complex technology involving significant human, finance and operational considerations. In Northern Ontario, many communities are struggling with the desire to implement GIS and the realities of their financial constraints and limited resources.

This paper provides a description of GIS technologies and applications; reviews the status of municipal GIS across Northern Ontario and; presents key success elements that should be considered by municipal governments and their staff when developing GIS strategies and networks. These key elements should also be helpful to government funding organizations when reviewing GIS funding proposals.

\section{Geographic information systems (GIS)}

\section{Definition}

A geographic information system (GIS), also known as a geospatial information system or geomatics, is a powerful computer-based system that allows users to capture, store, display, analyze and manage geo-referenced data. It enables one to view and interpret digital information in ways that reveal patterns and trends. A GIS can help answer questions and solve problems by allowing the user to look at complex data in a manner that is quickly understood and easily shared. GIS technology is used in a variety of functions including scientific research, asset management, municipal planning, tourism, criminal investigations, health services, historical research and even sales and marketing. GIS can also help emergency planners calculate emergency response times in the event of a natural disaster or help identify sensitive areas that need protection from pollution.

\section{Components}

A Geographic Information Systems consists of five very important components; computer hardware, GIS software, people, data and the operational model (MAIC 2004).

\section{Computer hardware}

The computer and its central processing unit (CPU) is the general hardware component of the GIS. It is usually attached to a very high capacity data storage unit such as a Storage Access Network (SAN), which is used to store the GIS program and its large data files. Other peripherals, such as digital scanners, may also be included to convert paper maps and documents, into digital data that is then integrated into and used within the GIS system. Most GIS systems 
also include a plotter which is used to print out large maps and graphics. Field workers often use Portable Global Positioning Satellite (GPS) to capture new GIS datapoints or to enhance commercially purchased datasets (see Appendix 1 - GIS Hardware Components).

\section{GIS software}

The GIS software module is very important as it is responsible for generating, analyzing, manipulating and displaying the geographical information. When selecting GIS software, users consider several important factors including "user friendliness", cost-effectiveness, system compatibility and software documentation. GIS software is also evaluated in terms of the potential user's needs and requirements in consideration of their work procedures, production requirements, and organizational context. There are several producers of GIS software including Environmental Systems Research Institute (ESRI), Autodesk, Clark Labs, Mapinfo Corporation, Bentley Systems, PCI Geomatics and others. The technical features of GIS software varies significantly from one product to another and, for this reason, many perspective users engage the services of a consultant to assist with the selection of their software.

\section{Data}

The most important and delicate component of a GIS is the data. This spatially referenced information has many important uses. It helps municipal planners understand where things are and how they relate to other things in the same area. GIS data can be purchased from data organizations, government departments and commercial vendors or it can be produced in-house or a combination of both. Significant time, money and resources are allocated to collecting, storing, analyzing, securing and ensuring the integrity of the GIS data.

\section{People}

GIS technology is useless without people power. Users may include specialists who design and support the systems, data collectors that populate the GIS and regular office workers that need to refer to the GIS information in order to complete a routine office task or client service.

Regardless of the user and application, proper user training is essential for ensuring effective use of a GIS system (Hearnshaw, 1993).

\section{Operational Models and Procedures}

In order to ensure that GIS equipment, data and resources are used appropriately and effectively, it is imperative to clearly define the operational model and procedures. Unfortunately, these two elements are often given due consideration only after organizational and operational problems are encountered. Understanding how the system is to be used, by whom, for what purpose and 
within what operational parameters is important in ensuring the smooth operation of any GIS network.

\section{Data linkages}

One of the most powerful functions of a GIS is its ability to link geo-referenced data from various databases and to display this information in a layered fashion on a map. This powerful function enables users to access and view a variety of complex geo-referenced (mapped) information in a way that is visually appealing and easy to understand, thereby facilitate the decision-making process. Data is stored in a layered format which is then accessed by the GIS and displayed overlaid one on top of the other (Birkin, M., Clarke, G., Clarke, M. and Wilson, A. 1996). For example, a municipality may be considering allocating a certain parcel of land for a housing development. A GIS could help them visually understand how this housing development would affect bus routes, traffic flows, infrastructure costs, road cleaning costs and even the tax base.

\section{Municipal GIS: Potential benefits and applications}

As previously stated, the ability of a GIS to provide effective data linkages make it a powerful tool for performing complex analysis. In addition to improving municipal business processes and facilitating better decision making, GIS is also used to promote economic development. By integrating infrastructure information such as water, sewer, phone, hydro and gas services with municipal land use information, such as official plan and zoning information, businesses can identify economic development opportunities. GIS can also be used to promote tourism by enabling the public to find the location of businesses and points of interest, such as trails, parks and beaches, as well as important social services, such as hospitals and schools. The ways in which GIS can be used as an economic development tool are as varied as the communities themselves. Some of the more popular economic development applications supported by GIS include:

- Municipal Asset Management - understanding what municipal assets and infrastructure are available and where they are located enhances the economic development officer's ability to "sell" the communities positive social and commercial attributes

- Suitability Analysis - GIS enables economic developers to determine the best areas of growth and to more effectively match the needs of commercial developers with the appropriate locations. GIS can equally effective in determining locations that would not be suitable for a particular development (i.e. due to environmental sensitivities, negative effects on local traffic, lack of infrastructure, etc...) 
- Policy Making - GIS can be used to help community leaders determine which areas of the community are over developed and what areas are stagnating. This can help them decide how to distribute their scarce resources more effectively.

- Marketing - Using GIS for marketing activities can result in a significant return on investment for municipalities. Attracting one significant employer to a municipality can easily justify the cost of a GIS. The system allows economic developers to quickly and professionally showcase their community's assets and unique features to businesses looking to re-locate their operations. (Roose. 2008)

- Strategic Planning - A GIS can capture and present municipal data from a variety of sources in a visually coherent manner. This helps municipal planners identify economic opportunities and challenges, which is an extremely important component of a municipality's strategic planning process (Lauritsen. 2001).

\section{Fednor's GIS study}

In 2007, FedNor ${ }^{2}$ conducted a study to determine to the level of GIS adoption by Northern Ontario communities. The study identified municipalities currently using GIS, examined some of the existing and developing municipal GIS partnerships and identified best practices (FedNor, iPlan Corp. 2007).

\section{Municipal GIS in Northern Ontario: Current status assessment}

The Fednor GIS Study defined municipalities as being GIS enabled if they had staff accessing or housing GIS hardware/software and if they updated their GIS data on an annual basis. The study determined that 38 municipalities in Northern Ontario currently use GIS technology (see Appendix 1 - Municipal GIS Status). These municipalities represent $25 \%$ of the North's152 municipalities. The total population of Northern Ontario's GIS-enabled municipalities is approximately 585,000 (70\% of Northern Ontario 839,549 residents, including unorganized municipalities and First Nations). The study also determined that there are an additional 20 municipalities that have completed GIS strategic plans, but have not yet implemented GIS. In total, there are 58 municipalities in Northern Ontario that are either using GIS or are in the process of implementing GIS. This represents $74 \%$ of the population, but only $38 \%$ of the municipalities in Northern Ontario. The GIS-enabled communities vary considerably in there approach to using the technology.

\footnotetext{
${ }^{2}$ FedNor is the federal government regional development organization in Ontario. Through it Northern Ontario Development Program (NODP), FedNor support many economic development initiatives including Information and Communications Technology (ICT) applications like GIS.
} 
These differences include, but are not limited to:

- types of automated business processes;

- standards and quality of data;

- web-based vs. desktop GIS functionality;

- public access to GIS system;

- outsourced vs. internal GIS support and management;

- partnerships vs. individual municipalities;

- partnerships agreements and funding formulas;

- human and financial resources; and

- project deployment timelines.

It is interesting to note that five of the 38 GIS-enabled municipalities account for $52 \%$ of the total population of Northern Ontario. These larger municipalities include the City of Greater Sudbury (155,219), Thunder Bay $(109,016)$, Sault Ste. Marie $(74,566)$, North Bay $(52,771)$ and Timmins $(43,686)$. The GIS functionality, organizational structure and GIS operating budgets within each of these five larger municipalities vary significantly. For example, the Sault Ste. Marie Innovation Centre's Community Geomatics Centre is not a department of the City of Sault Ste. Marie, however, it provides GIS services to the City as well as to other Northern Ontario communities. In 2005, the City of Timmins began implementing GIS and has taken a leadership role on behalf of 7 communities in developing a municipal GIS consortium called the Northeastern Ontario GIS Centre of Excellence. (FedNor, iPlan. 2007).

\section{Municipal GIS partnerships}

Most municipalities across Northern Ontario recognize the potential economic development benefits of GIS, however, many of the smaller communities (population of less than 20,000) have identified serious impediments to deploying the technology. The two major issues are 1) the lack of human resources with the necessary skill sets to support GIS and; 2) the lack of financial resources. To address these challenges, many of these smaller municipalities have opted to develop cost-effective partnerships with other similar municipalities. The purpose of these consortia is the share in the cost of acquiring the GIS hardware, the GIS software and datasets, and the necessary talent or services to support the system components. Also, to help reduce the financial burden to individual municipalities, many of these municipal GIS consortia or networks have collectively sought financial support from funding programs such as FedNor, the Northern Ontario Heritage Fund Corporation (NOHFC) ${ }^{3}$ and GeoSmart ${ }^{4}$

\footnotetext{
${ }^{3}$ NOHFC is provincial funding program administered by the Ministry of Northern Development and Mines.

${ }^{4}$ GeoSmart was a province of Ontario initiative, led by the Ministry of Natural Resources that provided funding to support the development of regional GIS partnerships and the deployment of GIS solutions.
} 
Between January 2004 and June of 2008, six municipal partnerships were formed in Northern Ontario. Their main objective? To share the risks and the costs associated with deploying and managing municipal GIS solutions. There are currently 48 municipalities involved in these projects, representing a total population of 190,879 . The six municipal GIS partnerships are:

1. Blue Sky Municipal Geographic Information System Partnership

2. Eastern Algoma GIS Initiative

3. District of Muskoka

4. Northeastern Ontario GIS Centre of Excellence

5. Northern Information Technology Geomatics Cooperative

6. West Parry Sound Geography Network

Each of these partnerships has unique attributes, in terms of their technologies, organizational structure, objectives, functionality and budget.

\section{Blue Sky municipal geographic information system partnership}

In 2006, this network, led by Blue Sky Economic Growth Corporation (also known as Blue Sky Net) developed a GIS strategic plan for more than a dozen communities across the Nipissing region. The GIS network is now in the process of being deployed and is expected to be fully operational some time in 2009. Blue Sky Net is coordinating the deployment of the network and the on-going management of the GIS will be out-sourced to an Application Service Provider (ASP) ${ }^{5}$. The consortium currently involves 18 municipal partners across the Nipissing region including Armour, Bonfield, Burk's Falls, Callander, Calvin, Chisholm, East Ferris, Kearneym, Machar, Magnetawan, Mattawa, Papineau-Cameron, Perry, Powassan, Ryerson, South River, Strong and Sundridge. Each participating municipality is responsible for populating and maintaining its own community data. This project began in 2007 and was developed in two stages. The first stage involved the development of a business plan which defined the network structure, technology, partnership agreements, costing model and governance structure. The second stage (currently underway) involves the implementation of the GIS hardware/software, training and data collection/conversion. The network is expected to be fully operational in 2009. The group meets regularly to discuss network related issues. While most of the central support and management functions will be provided by the ASP, the partnering municipalities have committed some staffing resources to assist with data input and conversion activities.

\section{Eastern Algoma GIS initiative}

The Town of Blind River is the lead for the municipal GIS network. It currently involves a total of four municipalities including Blind River, Huron Shores, North Shore and Spanish. The

\footnotetext{
${ }^{5}$ Application Service Provider (ASP) is a third-party (out-sourced) business that provides centralized network, technical and software application support services to clients.
} 
network's GIS technology has been implemented and is locally hosted and maintained in Blind River. GIS functionality is provided to partners through locally installed shareware software and GIS information is updated on a quarterly basis. The partners hold monthly steering committee meetings, consisting of councilors and senior management, as well as monthly user group meetings. The group has a licensed copy of the Ontario Parcel and Municipal Property Assessment Corporation data and is a member of the Ontario Geospatial Data Exchange and Ontario Road Network. Network partners have started capturing infrastructure data and will be expanding the system to include land-use planning and environmental assessment tools as well as a web-based Industrial, Commercial, Investment and Economic Development tool. Network implementation began in April 2005 and was completed by 2006. Network expansion is currently underway and will soon include two new partners - Mississauga First Nation and Serpent River First Nation.

\section{District of Muskoka}

The District of Muskoka is an upper tier municipal government that is supporting this GIS initiative on behalf of 6 lower tier municipalities including Bracebridge, Georgian Bay, Gravenhurst, Huntsville, Lake of Bays and Muskoka Lakes. The District provides centralized operational and technical support services to its GIS partners. The group has created and maintains its own parcel fabric ${ }^{6}$ and uses the system primarily for planning purposes. Infrastructure data is not currently available on the system. The group intends to provide webbased access to the GIS in the near future. The municipal partners are involved in inputting new GIS data into the system. The group developed its own GIS strategic plan and implemented the system using internal resources.

\section{Northeastern Ontario GIS Centre of Excellence}

This GIS partnership is led by the City of Timmins and involves six other municipalities including City of Kirkland Lake, City of Iroquois Falls, Township of Black River - Matheson, City of Temiskaming Shores, Municipality of Temagami, Town of Moosonee. The system is currently being deployed and is expected to be fully operational by December 2009. Like the District of Muskoka's GIS consortium, this group has opted to create and maintain its own parcel fabric. An ASP designed the network model and is responsible for implementing the system and hosting the GIS environment. The partners have all signed a partnership agreement and the group meets on a monthly basis to discuss user needs and network issues. This GIS network was also developed in two stages. From October to November 2004, the City of Timmins developed a municipal GIS strategic plan in consultation with neighbouring communities.

\footnotetext{
${ }^{6}$ Parcel fabric is one of the foundations of the municipal GIS and provides the geographic component for property information including ownership, legal descriptions, and assessment information.
} 
Network deployment began in January of 2006 and is expected to be fully operational by December 2009.

\section{Northern Information Technology Geomatics Cooperative (NITGC)}

This GIS consortium is led by the Town of Wawa and involves five other municipal partners including Chapleau, Dubreuilville, Hornepayne, Manitouwadge and White River. The network's GIS system is fully implemented and is being hosted and maintained by the Town of Wawa. GIS functionality is being provided to the partners though a web based GIS technologies. The NITCG have a partnership agreement that details funding requirements and commitments for network infrastructure (hardware, software, data licensing), network communications and operational costs (staffing). Monthly meetings are conducted between the Mayors of the partnering communities as well as members of the network's User Group. Municipal partners are actively involved in inputting new GIS data into the system and have allocated staffing to support these activities. This project began in January 2004 and was fully operational by January of 2005.

\section{West Parry Sound Geography Network (WPSGN)}

The Township of the Archipelago initiated the development of this municipal GIS and is providing hosting and network maintenance support services to the partners. The WPSGN consists of 7 municipal partners including the Archipelago, Carling, McDougall, McKellar, Parry Sound, Seguin and Whitestone. The Archipelago provides GIS functionality to the partners through a web-based GIS. The group has purchased licensed copies of the Licensing Ontario Parcel and Municipal Property Assessment Corporation data but has not yet integrated infrastructure data. The partners have developed and signed a Memorandum of Understanding (MOU) that defines their partnership structure and responsibilities. The group meets regularly to discuss network related issues. This municipal GIS partnership was also developed in two stages. The first stage (from July 2004 to March 2005) involved the development of a business plan. This plan defined the network structure, technology, partnership agreements, costing model and governance structure. In August 2005, the WPSGN began the implementation phase, which was completed five months later.

\section{Independent municipalities}

The FedNor GIS Study also determined that several municipalities across Northern Ontario use GIS, but were not members of any municipal GIS consortium or partnership. These municipalities include Dryden, Greater Sudbury, Greenstone, Kenora, Machin, Marathon, North Bay, Sault Ste. Marie, Terrace Bay and Thunder Bay (FedNor, iPLan. 2007). These communities have determined that they have the financial and human resources required to 
successfully implement their own GIS solution. They are not working with other municipal partners at this time (as of June 2008). However, many of these municipalities have said they are considering expanding their respective systems to include other partners in order to cut costs and realize economies of scale.

\section{Best practices and success elements}

There are many factors that have helped Northern Ontario municipalities implement and maintain functional GIS environments. Successfully deployed GIS systems are viable, costeffective, provide a return on investment and ultimately, meet the adopters defined GIS objectives. While municipalities, partnerships and GIS deployment projects vary significantly across Northern Ontario, it is possible to identify a few important factors and considerations that will help users achieve cost and operational efficiencies, reduce risks and ensure long-term system viability.

\section{Resources: Funding, staffing, talent}

Once a municipality has determined its GIS needs, it is very important to realistically assess the financial and human resources available to develop, implement and maintain the GIS. Most, smaller municipalities do not have the financial and human resources, or the internal expertise, to support a sophisticated technology like GIS. These communities should consider partnering with other municipalities to reduce costs and risks, improve operational efficiencies and increase funding opportunities. Larger communities with necessary resources to develop and implement their own solutions should also consider partnering with other smaller communities as it may help to provide additional revenues that will enable them to accelerate the expansion or upgrading of their networks.

\section{Partnerships}

Municipalities that do not have the necessary financial or human resources to successfully implement a GIS on their own and decide to partner with other communities, should ensure that all partners agree to enter into a clearly defined partnership agreement or Memorandum of Understanding (MOU), as well as long-term funding and service level agreements. The agreements should identify the scope of services, define operational policies, roles and responsibilities, provide an organizational chart, job descriptions (if applicable), performance measures, budget requirements and financial obligations from the partners. The agreements should also be approved by the Councils of all partnering municipalities prior to implementing the GIS. 


\section{Strategic plan}

GIS is complex, expensive and it requires careful consideration and planning. To ensure that a GIS meets the needs of its users, municipalities need to develop a strategic plan. This "roadmap" will ensure that the users' needs are clearly defined and will ensure that a reasonable approach is followed when implementing the proposed solution. The Strategic Plan needs to address a number of elements including: technical design, operational model; HR implications; training needs; technology and operational costs, financial implications (budget); funding sources; maintenance; future upgrades and expansions (see Appendix 2 - Sample Strategic Plan Template).

Part of the Strategic Planning process should also include a competitive Request for Proposal (RFP $)^{7}$ process to select an appropriate GIS solution that meets the needs of a municipality or the GIS consortium (see Appendix 3 - Sample GIS RFP document). To facilitate this process, an RFP working committee should be also organized. This committee should be responsible for defining the RFP's terms of reference, developing the RFP document, developing the evaluation criteria for the proposals, evaluating the proposals and recommending a vendor.

\section{Contingency planning}

The operational and organizational structure of a partnership should address issues such as what happens should the lead municipality choose not to continue to support the partnership; what happens should a partner choose to leave the partnership; what happens should key staff leave. Cost and operational implications should be determined and remedying actions defined before they are encountered in order to minimize the impacts of such events.

\section{Accountability}

GIS partnerships should include full-disclosure and accountability related to GIS network operations and costs. The lead partner or Application Service Provider (ASP) should provide the other partners with annual status reports, identifying the activities performed as well as effort and costs associated with implementing, managing and maintaining the GIS network, technology and applications.

\section{Training}

As previously stated, people play an important part in developing, supporting and expanding any GIS. Whether the user is a community resident, municipal leader, economic development officer

\footnotetext{
${ }^{7}$ Request for Proposals (RFP) - a document that an organization posts to elicit bids from potential vendors for a product or service.
} 
or technical support specialist - they all require training. Obviously, a GIS technical support person will require a higher level of training than day-to-day GIS users. They may be required to have a college diploma or university degree in GIS in order to meet the needs of the municipality and/or GIS partnership and its users. Additional training opportunities should be explored for these people in order to ensure they stay current and are able to meet the future needs of the municipality and/or municipal GIS network.

End-users also require training in order to use the system effectively and to reduce their demands on the technical support team. Usually, end-user training is provided by the vendor, however, it is advisable to seek out additional training opportunities to ensure they are aware of the newest GIS applications and operational functions. Staff GIS training should be considered an investment in operational efficiency and effectiveness. Municipal leaders, politicians and the general population (if GIS is available to the public via the web) should also be considered as it will support global buy-in and promote system usage.

\section{Parcel data}

Whenever possible, municipalities should consider purchasing commercially available parcel data rather than creating their own. The cost, time and resources required to create original parcel data is significant and may not be initially apparent. A careful analysis of the cost implications and efficiencies is recommended before a municipality decides to create its own parcel data as opposed to licensing with commercial data producers such as the Ontario Parcel data from Teranet and the Municipal Property Assessment Corporation (MPAC). Municipalities may have concerns in regards to the data quality data quality provided through the Ontario Parcel, however, creating parcel data by other means may not improve data quality to a sufficient point to justify the expense.

\section{Conclusion}

Over the years, Geographic Information Systems have played an increasingly important role in supporting municipal governments and their staff. Today, some of the more popular municipal GIS applications include Suitability Analysis, Policy Making, Marketing and Strategic Planning. While the benefits of using GIS for municipal planning and economic development applications are apparent to most municipalities across Northern Ontario, many have found it challenging to deploy the technology as they do not have the necessary financial or human resources, nor the internal expertise to do so. In order to mediate these challenges, several communities have chosen to partner with other municipalities to establish municipal GIS networks. These networks have enabled small communities to implement sophisticated GIS technology in a cost-effective manner. Over the past four years, six municipal GIS partnerships have been formed in Northern Ontario involving 48 municipalities and representing a total population of over 190,000. 
Lessons were learned by these pioneering groups and important considerations and success elements were identified including; the need to ensure that adequate resources (financial, human, talent) are available; the importance of forming partnerships where appropriate; contingency planning; accountability between partners and users; training and; the need to use available parcel data whenever possible. These factors may not necessarily guarantee success, but they will help municipalities develop a strong GIS business plan and will increase the likelihood of a successful deployment and the long-term viability of the GIS solution.

\section{Author Biography}

Théo Noel de Tilly is a Initiatives Officer at FedNor - Industry Canada in Sudbury, Ontario.

\section{References}

Antenucci, J.C., Brown, K., Croswell, P.L. and Kevany, M.J. (1991). Geographic Information Systems: A Guide to the Technology.

Bernhardsen, T. (1999). Geographic Information Systems: An Introduction.

Berry \& Associates. (2008). The GIS Primer: An Introduction to Geographic Information Systems. Implementation Issues and Strategies. Retrieved from: http://www.innovativegis.com/basis/primer/implissues.html

Birkin, M., Clarke, G., Clarke, M. and Wilson, A. (1996). Intelligent GIS: Location Decisions and Strategic Planning.

Blue Sky Net, cgis. (2007). GIS Strategic Plan for Municipalities in the Blue Sky Region.

Campbell, H., Craglia, M. and Masser, I. (1996). GIS Diffusion: The Adoption and Use of Geographic Information Systems in Local Government in Europe.

EDAC. (2008). Economic Development Association of Canada. Retrieved from: http://www.edac.ca

FedNor and iPlan Corp. (2007). FedNor GIS Study Report: Northern Ontario.

Florio M.L. (2006). An Evaluation of Geomatics for Economic Development. University of Waterloo: Local Economic Development Masters Research Paper.

GIS Development. (2000). GIS Time Line. GIS Development - GeoSpatial Portal. Retrieved from http://www.gisdevelopment.net/history/1960-1970.htm 
Hearnshaw, H.M. \& Medyckyj-Scott, D. (1993). Human Factors in Geographic Information Systems.

Jarvis, I. \& McDonald, K.B. (1993). Land Planning Use: Using GIS to Evaluate Land Suitability for Agriculture. The Canadian Conference on GIS - 1993 Proceedings, pp. 550-558.

Kowalska, M. (1993). The Use of Geographic Information Systems to Evaluate the Environmental Hazard of a Heavily Industrialized Area. The Canadian Conference on GIS: 1993 Proceedings, pp. 365-370.

Lauritsen, K. (2001). Municipal GIS Implementation Planning and Strategies: Evidence from North American Case Studies.

McDermott, D. (2006). Animate Time and Space to Visualize Economic Change. GEO World.

Mine Action Information Center (MAIC). (2004). Components of a GIS. James Madison University. Retrieved from http://maic.jmu.edu/sic/gis/components.htm.

Obermeyer, N.J. \& Pinto, J.K. (1994). Managing Geographic Information Systems.

Otawa, T. (2004). Maximizing the Power of Geographic Information Systems (GIS) in Applied Land Informatics.

Paul, L. \& Sussman, R. (1993). Municipal Applications (of GIS) and Market Research. The Canadian Conference on GIS:1993 Proceedings, pp. 1-11.

Rebman, S. (1993). GIS Infrastructure. The Canadian Conference on GIS - 1993 Proceedings, pp. 496.

Roose, D. (2008). Customizing GIS for Economic Development. Retrieved from: http:/gis.esri.com/library/userconf/proc97/proc97/to200/pap163/p163.htm

Sussman, R. (1994). Municipal GIS: People over Technology. The Canadian Conference on GIS:1994 Proceedings Volume 1, pp. 9-17. 
Appendices

Appendix 1: GIS hardware components

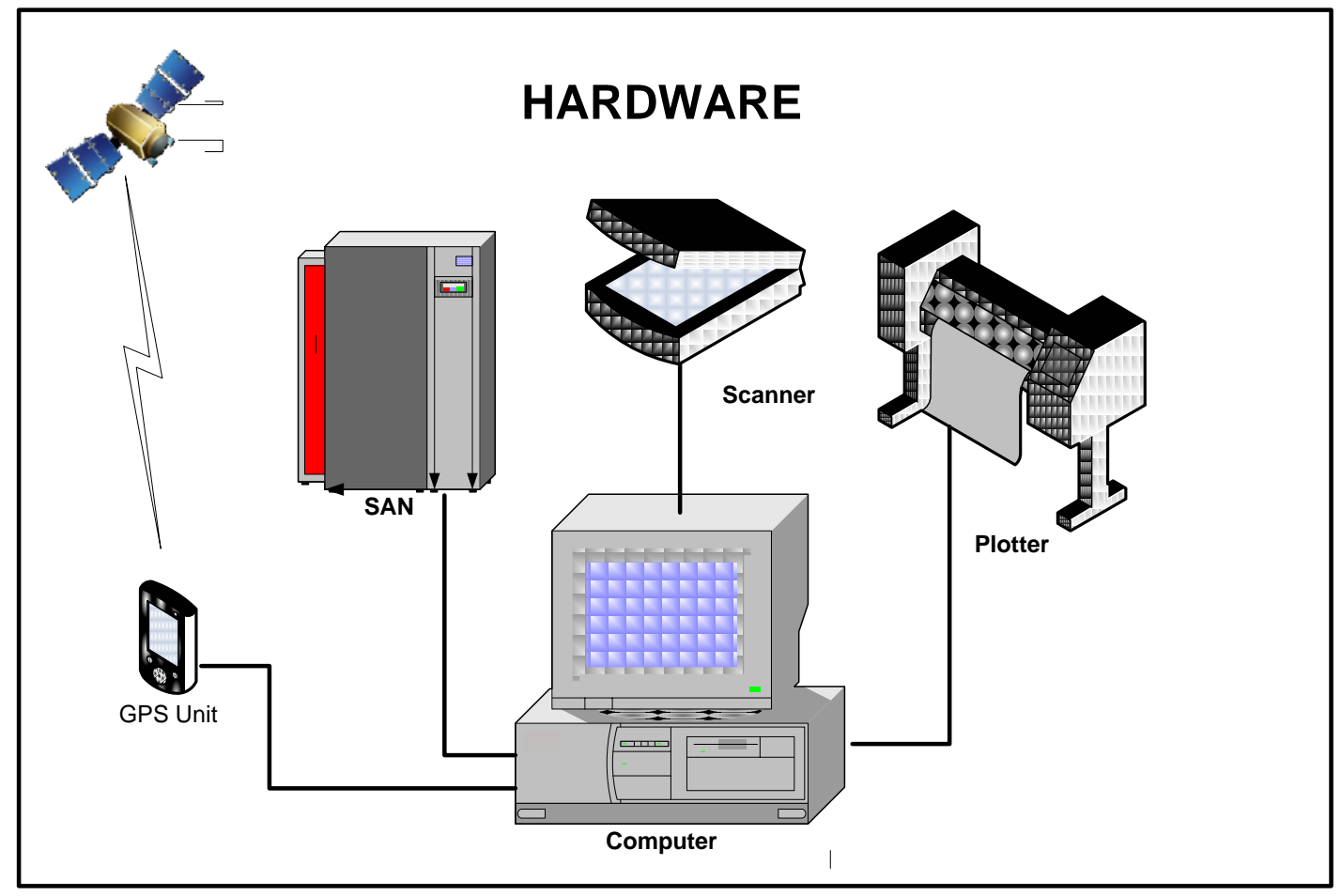




\section{Appendix 2: Municipal GIS status}

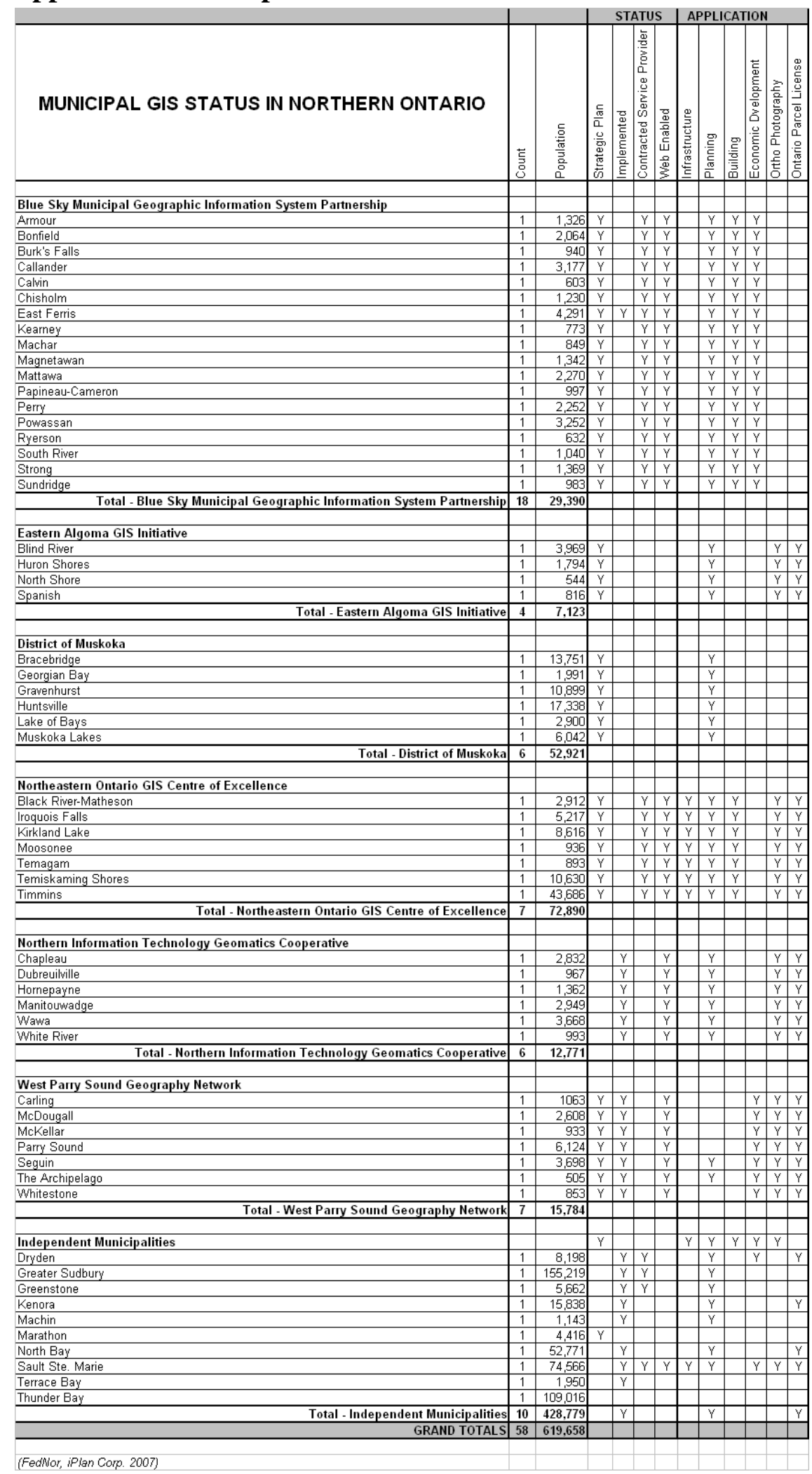




\section{Appendix 3: Sample strategic plan template}

\section{GIS Strategic Plan}

1. Executive Summary

2. Background

3. Current Status Assessment

4. Options

5. $\quad$ SWOT Analysis

6. Proposed GIS Solution

7. Benefits

8. Implementation Plan

9. Financial Implications

10. Human resources Implications

11. Conclusion 


\section{Appendix 4: Sample GIS request for proposal template}

\section{Request for Proposals}

1. Title Page

2. Introduction

3. Timelines and Contact Information

4. Background

5. Objectives

6. Deliverables

7. Demographics

8. Submission Requirements

9. RFP Questions

10. Evaluation Criteria

11. Conditions 